\title{
Na ponta do bico: o jomalismo hiperlocal na região do Bico do Papagaio (TO)
}

\section{Alan Milhomem da Silva ${ }^{1}$ Liana Vidigal Rocha ${ }^{2}$}

\section{Resumo:}

Balizado por uma discussão teórica sobre jomalismo hiperlocal, o trabalho identifica e apresenta a produção de dois sites do Bico do Papagaio, mic rorregião do extremo norte do Tocantins. Os veículos foram a nalisa dos durante cinco dias seguidos no mês de junho de 2017. Foi possível verific ar que o Folha do Bico e o Voz do Bico exploram caracteństicas do hipenocalismo a se voltarem para cada município em específico da microrregião, noticiando os a contecimentos da comunidade local, que não conta com grandes veículos de comunic ação. Foi constatado, a inda, que os sites não exploram as possibilidades oferecidas pela web, como a produção de vídeos, galerias de fotos e outras na rrativas.

Palavras-chave: Webjomalismo. Hiperlocalismo. Bic o do Papagaio.

\section{Abstract}

Based on a theoretical disc ussion about hyperlocal joumalism, the paper identifies and presents the production of two sites of Bico do Papagaio, a micro-region in the extreme north of Tocantins. The websites were analyzed for five consecutive days in the month of J une 2017. It was possible to verify that Folha do Bico and Voz do Bico explore characteristic s of hyperlocalism when they retum to each specific municipality of the micro region, reporting the events of the local community, which does not have large communic ation vehicles. It was also verified that the sites do not explore the possibilities offered by the web, like videos production, photo galleries and other na rratives.

Keywords: Webjoumalism. Hyperlocalism. Bico do Papagaio.

1 Bacharel em Comunicação Social - habilitação em J omalismo (UFMA). Especialista em Assessoria de Comunicação Empresarial e Institucional (UFMA). Mestrando em Comunicação e Sociedade (PPGCom-UFT). Integrante do Grupo de Pesquisa em J oma lismo e Multimídia. Bolsista Capes. E-ma il: milhomemalan@gma il.com

2 Doutorado em Ciências da Comunicação pela ECA/USP. Docente do Programa de Pósgraduação em Comunicação e Sociedade da Universidade Federal do Tocantins. Ĺder do Grupo de Pesquisa em Jomalismo e Multimídia (CNPq). E-mail: lividiga l@uol.com.br

Revista Pauta Geral-Estudos em J omalismo, Ponta Grossa, v. 4, n. 2, p. 3 -20. J ul/Dez 2017. 


\section{Introdução}

A partir da década de 1990, a internet provocou diversas transformações nos meios de comunicação, afetando não só o fazer jornalístico, mas as empresas, os profissionais e o público, que criou novos hábitos e formas de consumo. O pano de fundo dessas mudanças são as transformações sociais que originaram a sociedade em rede, como denomina Castells (2007). Para o autor, essa era digital ou da informação é caracterizada, do ponto de vista socioeconômico, em três traços: produção de conhecimentos e gestão da informação; formação em rede eletronicamente potencial; e a globalização. Assim, "a internet é o coração de um novo paradigma sociotécnico, que constitui na realidade a base material de nossas vidas e de nossas formas de relação, de trabalho e de comunicação" (CASTELLS, 2003, p. 287).

Diante dessas mudanças provocadas pela sociedade em rede, há uma tendência de homogeneização na sociedade e na produção jornalística. Porém, tem surgindo novas estratégias que favorecem a proximidade, um exemplo é o jornalismo hiperlocal. Este é entendido como uma tendência à exploração dos temas e interesses locais, voltados para subúrbios, pequenas cidades, vilas e bairros. Assim, este artigo apresenta uma discussão teórica sobre a produção hiperlocal e analisa a produção de dois sites da microrregião do Bico do Papagaio (TO), por meio da descrição do conteúdo dos dois veículos durante cinco dias seguidos em junho de 2017. O trabalho adota os procedimentos da Análise de Conteúdo propostos por Bardin (2011), assim o material foi coletado e depois analisado por meio de categorias. Portanto, trata-se de uma pesquisa do tipo descritiva e quantitativa.

\section{O hiperlocal no webjornalismo}

Nesse cenário de mudanças, adaptações, novas demandas e de um mundo cada dia mais interligado, há uma tendência de homogeneização de culturas, identidades e, no jornalismo, de conteúdos, além de uma intensificação de fluxos informacionais. Em contraponto a esse processo ocorre a valorização do local, uma busca para se referenciar e identificar (LEMOS; PEREIRA, 2011). Nesse sentido, Hall (2006, p. 80) considera que a "globalização caminha em paralelo com um reforçamento das entidades locais, embora isso ainda esteja dentro da lógica da compreensão espaço-tempo". Além disso, o autor 
afirma que a tendência à homogeneização global coabita com a valorização da riqueza e diversidade do local.

As possibilidades proporcionadas pela cultura da convergência (JENKINS, 2009), como a mudança no comportamento das pessoas e na produção e circulação de conteúdos, estimulam o surgimento do jornalismo hiperlocal (BRONOSKY; CARVALHO, 2014). Considerado uma tendência mundial, nesse tipo de jornalismo as comunidades podem se expressar e criar laços de identidade. Tudo isso é potencializado por meio das plataformas multimídias digitais (LEMOS; PEREIRA, 2011). "Em 'A Cauda Longa', Chris Anderson (2006) já chamava a atenção para o fato de a tecnologia converter o mercado de massa em milhões de nichos, e é nessa segmentação que o jornalismo hiperlocal pega carona" (ROCHA et al, 2015, p.4).

De acordo com Varela (2007), o jornalismo hiperlocal foi um termo criado nos Estados Unidos, em 1991, para definir a cobertura televisiva voltada para o bairro ou para a comunidade local. No Brasil, Zago (2009) destaca que uma das primeiras experiências de prática hiperlocal de grande destaque pode ser observada no portal Bairros.com, criado em 2008 e vinculado à Globo.com. O site disponibiliza, com a colaboração de leitores, blogs e moradores, notícias referentes de pequenos espaços da região metropolitana do Rio de Janeiro.

Mesmo sem uma definição ainda muito clara e de consenso, o jornalismo hiperlocal pode ser caracterizado como uma modalidade de cobertura jornalística com produção de conteúdos sobre uma comunidade específica, que conta com a colaboração da comunidade envolvida e permite, ainda, a exploração de recursos digitais multimídias albergando textos, produção audiovisual, fotografias e infográficos. Além disso, o jornalista precisa ter habilidades multimídias, e o público passa a colaborar e produzir conteúdos (LEMOS; PEREIRA, 2011).

Bianchi e Moraes Júnior (2016) destacam que a imprensa hiperlocal é uma forma de fazer jornalismo mais próximo da comunidade, pautando temas específicos e com foco em uma determinada população. É colocar em prática o conceito de estar a serviço da comunidade, isto é, divulgar informações que tratam de assuntos que afetam diretamente determinado público. Nessa produção hiperlocal, devido a maior aproximação com o público, há a possibilidade de se explorar mais a humanização nas produções jornalísticas, como a valorização dos personagens, e um entendimento maior os valores e princípios da comunidade onde o veículo está inserido. "A proximidade da matéria com o 
leitor é atingida pelo reconhecimento do leitor com a personagem e com o acontecimento que está sendo retratado" (BIANCHI; MORAES JÚNIOR, 2016, p.6).

Outro componente importante do jornalismo hiperlocal é a participação do leitor, que antes era visto como um ser passivo, mas agora tem papel importante na produção de conteúdos. Mesquita (2014, p. 7) afirma que, hoje, a audiência é formada por cidadãos que estabelecem uma relação ativa com os veículos de comunicação, envolvendo-se e sendo envolvidos nos processos jornalísticos, além disso, possui capacidade de propagação da informação, de ação, de produção, de transformação e de amplificação. Mas Varela (2007) alerta que essa colaboração não exclui a produção dos profissionais, pelo contrário, ela acrescenta no trabalho dos jornalistas.

Assim, Rocha et al (2015) destacam que não são apenas possibilidades para empreender, mas o jornalismo hiperlocal é uma possibilidade de praticar e resgatar as técnicas do jornalismo comunitário e aliar as novas tecnologias. "O grande desafio é ser capaz de inovar na cobertura, unir-se aos moradores, e fazer com que o cidadão se interesse pelo seu próprio cotidiano" (ROCHA et al, 2015, p. 5).

Nesse ecossistema midiático, que é convergente, conectado e globalizado, percebe-se que o local e o global não são extremos opostos, mas espaços que coabitam e interagem entre si. Como afirma Camponez (2002), o local é o lugar de compromissos comunicativos. E López García (2008) vai além, o autor afirma que essa proximidade no local não deve ser entendida apenas como uma vertente geográfica, mas também com vertentes sociais, culturais e, até, psicológicas ${ }^{3}$. Ao mergulhar no "universo da comunidade", o jornalismo hiperlocal tem a oportunidade de conhecer as "mentalidades, hábitos, modos de viver, níveis de vida, preocupações culturais e sociais" da sua localidade (CAMPONEZ, 2011, p. 40).

\section{Bico do Papagaio: algumas considerações}

Porta de entrada para a Amazônia Legal, a microrregião do Bico do Papagaio fica no extremo norte do Tocantins, na divisa com os estados do Pará e Maranhão e na zona de confluência dos rios Araguaia e Tocantins. A microrregião é marcada pelas atividades econômicas de subsistência, a cultura cabocla e sertaneja, a forte tradição de

3 “A hora la proximididad hay que entender la no sólo en su vertiente geográfica, sino ta mbién en sus vertientes social, cultural o, inc luso, psic ológica" (LÓPEZG ARCíA, 2008). 
REVISTA PAUTA GERAL

ESTUDOS EM JORNALISMO

10.5212/Revista Pauta Gera I.v.4.i2.0001
四

PautaGeral

Estudos em Jornalismo

associativismo e a diversidade social, com a presença de índios, assentados, pescadores, extrativistas e artesãos. Outra característica da localidade é a proximidade entre os municípios e a baixa densidade demográfica. É também uma área de transição entre a fauna e a flora do Cerrado e da Amazônia.

Com uma cultura popular rica, o extremo norte do Tocantins é caracterizado pela religiosidade, festejos tradicionais e a cultura rural, ligada a agricultura, pecuária e extrativismo, com destaque para a extração do coco babaçu. A microrregião também é marcada pela construção e a pavimentação da rodovia Belém-Brasília, nos anos 50 e 60, que impulsionaram o aumento populacional. Os imigrantes que passaram a habitar essa região do Tocantins eram, na maioria, nordestinos.

Outra característica da região são as marcas dos conflitos entres fazendeiros, grileiros e posseiros. Entre 1970 e 1990 esses conflitos foram intensos e provocaram muitas mortes, entre elas a do padre Josimo, em 1986. O líder religioso atuava na luta pela terra no Bico do Papagaio. Ele foi morto por pistoleiros encomendados por grileiros e acabou se tornando um mártir na disputa pela posse de terra nos anos $80^{4}$. Outro caso de destaque foi a Guerrilha do Araguaia (1972-1974), na divisa entre o Tocantins (antigo Goiás) e o Pará (CLEMENTINO; MONTE-MÓR, 2004).

Hoje, há poucas terras livres, sendo que a pobreza e as más condições de vida caracterizam essa área onde predominam a pecuária extensiva e a produção familiar de subsistência. Em contraste, impõem-se ao norte os projetos fundiários por meio das plantações de eucaliptos e madeiras nobres - teckas - e, ao sul, a cultura de soja, apoiados na circulação da Ferrovia Norte-Sul e no Terminal Graneleiro da Companhia Vale, localizado em Imperatriz - MA (MIRANDA; SANTOS, 2014, p. 79).

O Bico do Papagaio, atualmente, é formado por 25 municípios: Aguiarnópolis, Ananás, Angico, Araguatins, Augustinópolis, Axixá do Tocantins, Buriti do Tocantins, Cachoeirinha, Carrasco Bonito, Darcinópolis, Esperantina, Itaguatins, Luzinópolis, Maurilândia do Tocantins, Nazaré, Palmeiras do Tocantins, Praia Norte, Riachinho, Sampaio, Santa Terezinha do Tocantins, São Bento do Tocantins, São Miguel do Tocantins, São Sebastião do Tocantins, Sítio Novo do Tocantins e Tocantinópolis.

\footnotetext{
4 Informações obtidas em http://acervo.oglo bo.globo.com/fa tos-historicos/padre-jo simota va res-martir-na -d isputa-pela -posse-de-terra-no-pa is-nos-a nos-80-19264745 Ac essa do em 06 out 2017.
} 
REVISTA PAUTA GERAL

ESTUDOS EM JORNALISMO

10.5212/Revista Pa uta Gera I.v.4.i2.0001
四

PautaGeral

Estudos em Jornalismo

No município de Esperantina, o último do Estado na microrregião, distante $680 \mathrm{~km}$ da capital Palmas, fica localizado um dos pontos turísticos mais conhecido do Bico do Papagaio, o encontro das águas dos rios Araguaia e Tocantins. O local é muito visitado no período de baixa nas águas dos rios, que vai, geralmente, de junho a setembro. Essa época é conhecida na região como veraneio e muitos bancos de areia aparecem nos dois rios, formando as famosas "praias de água doce". No Bico do Papagaio, essa época é marcada por uma grande movimentação de turistas, que são atraídos pelas belezas naturais dessas praias e pelas programações culturais.

Dentre os municípios que formam a microrregião, dois se destacam por serem as maiores cidades e, consequentemente, os mais populosos. São eles: Araguatins e Augustinópolis. A localização geográfica dos municípios é demonstrada na Figura 01.

Figura 01: Microrregião do Bico do Papagaio e os municípios de Araguatins e Augustinópolis.

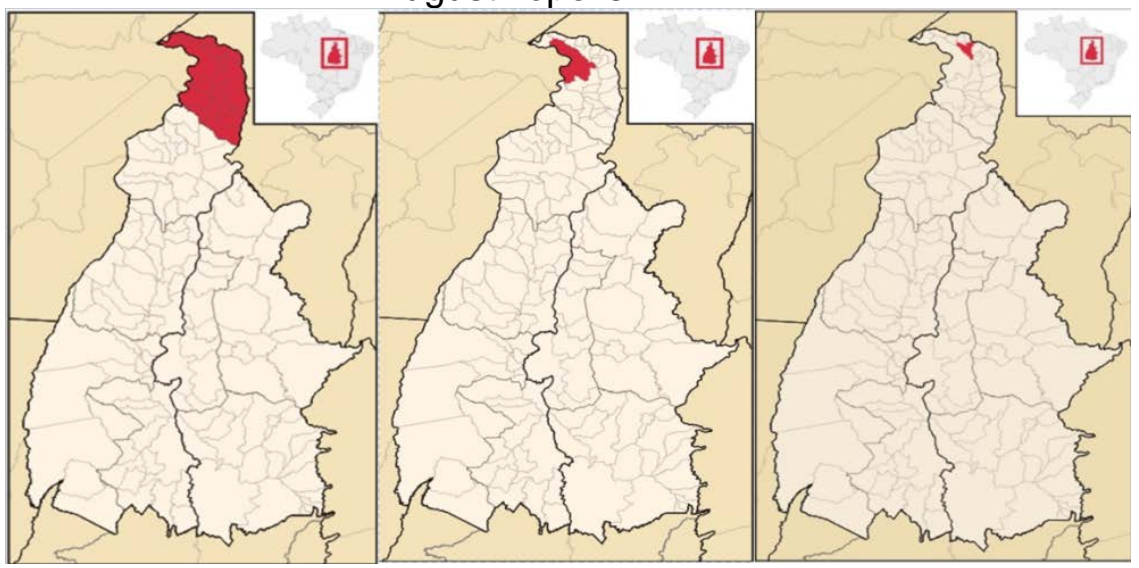

Fonte: Arte elaborada pelo autor com imagens da Wikipédia.

Localizado as margens do Rio Araguaia e na divisa com o Estado do Pará, a cidade de Araguatins, nomenclatura formada pela união do nome dos rios Araguaia e Tocantins, foi o primeiro polo educacional do extremo norte do estado. Hoje, é o município mais populoso da microrregião com quase 35 mil habitantes, segundo dados do Instituto Brasileiro de Geografia e Estatística (IBGE) ${ }^{5}$, referentes ao ano de 2016. Dado que coloca o município como o sexto mais populoso do estado. Em Araguatins fica a sede do site Folha do Bico.

5 Disponível em: ‘ttps://cidades.ibge.gov.br/v4/brasil/to/a ra gua tins/panorama >. Ac esso em: 20 jun. 2017. 
Outro destaque na região é Augustinópolis. Localizado no centro do Bico do Papagaio, o nome é uma homenagem a Augusto Pereira Costa considerado o primeiro morador e fundador do município. É a terceira maior cidade na microrregião do Bico do Papagaio com quase 18 mil habitantes, de acordo com o IBGE ${ }^{6}$. Se destaca regionalmente por ser um centro comercial e de saúde. Atualmente tem despontado como polo educacional, contando com uma faculdade e um campus da Universidade Estadual do Tocantins (Unitins). Possui destaque na rede hoteleira, cadeia de bares e restaurantes. É em Augustinópolis que fica a sede do site Voz do Bico.

\section{Procedimentos da Pesquisa}

Para alcançar o objetivo deste trabalho, identificar e apresentar a produção de dois sites localizados no Bico do Papagaio, microrregião do extremo norte do Tocantins, foi necessário definir as etapas de pesquisa descritas a seguir:

\section{Etapa I - Identificação do tema e do objeto}

Refere-se à etapa de escolha do assunto a ser tratado na pesquisa assim como o objeto a ser analisado. O jornalismo hiperlocal no Tocantins foi o ponto de partida da investigação por tratar-se de um tema ainda pouco explorado pelos pesquisadores. $O$ Tocantins possui oito microrregiões, sendo a do Bico do Papagaio a mais distante da capital Palmas. A preferência por esta localidade se deu em virtude do número de habitantes (cerca de 198 mil pessoas), da posição geográfica (divisa com Pará e Maranhão) e da cultura e economia diversificadas (religião, festejos, agricultura, extrativismo e disputa de terras). Já os sites foram selecionados a partir da nomenclatura alusiva à região e por possuírem editorias claramente nomeadas como Bico do Papagaio.

\section{Etapa II - Revisão Bibliográfica}

Após a definição do tema e dos objetos de pesquisa, foi feito um levantamento de publicações que tratassem sobre jornalismo hiperlocal, hiperlocalismo, webjornalismo hiperlocal, Tocantins e Bico do Papagaio. As informações coletadas em bancos de dados e sites de busca auxiliaram na construção do referencial teórico apresentado na parte

\footnotetext{
${ }^{6}$ Disponível em: <https://cidades.ibge.gov.br/v4/brasil/to/augustinopolis/panorama>. Acesso em: 20 jun. 2017.
} 
REVISTA PAUTA GERAL

ESTUDOS EM JORNALISMO

10.5212/Revista Pauta Gera I.v.4.i2.0001

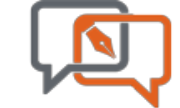

PautaGeral

Estudos em Jornalismo

inicial deste trabalho. Para tanto, foram utilizados artigos científicos, livros e matérias jornalísticas com o intuito de contextualizar o tema da pesquisa com a análise.

\section{Etapa III - Coleta dos dados e armazenagem}

Nessa fase, foi definido o período da coleta dos dados, entre os dias 26 e 30 de junho de 2017. O critério estabelecido foi que a coleta das matérias deveria ser feita durante cinco dias úteis e consecutivos independente da época do mês. Na sequência, foi feita a coleta do material direto de cada site, tendo a URL e o título da matéria armazenados em planilhas do Excel. Foi aberto um documento distinto para cada veículo e, para registrar as manchetes, foram criadas abas para cada dia da semana.

\section{Etapa IV - Identificação e categorização das matérias selecionadas}

Seguindo as orientações e etapas para a análise de conteúdo propostas por Bardin (2011), a pré-análise e exploração do material coletado ocorreram de forma concomitante, assim foram coletadas todas as matérias postadas nos cinco dias analisados. As publicações coletadas foram classificadas e caracterizadas de acordo com seu conteúdo, sendo divididas por assunto, narrativa apresentada, editoria e cidade onde aconteceu o fato noticiado.

\section{Etapa V - Análise e interpretação das informações}

A terceira etapa proposta por Bardin (2011) para a análise de conteúdo é o tratamento dos resultados, a inferência e a interpretação. Nessa fase, os dados coletados foram analisados de acordo com a discussão teórica apresentada anteriormente. As análises empreendidas sobre esses dados são detalhadas nos próximos tópicos.

\section{Dois sites e uma mesma lógica: o hiperlocalismo}

Com as novas possibilidades de produção jornalística que surgiram com o advento da internet, diversos veículos foram aparecendo ao longo do tempo e ganhando espaço com uma produção voltada para notícias gerais e globais, isso porque o fluxo de informação aumentou e o mundo passou a ser interligado via rede mundial de computadores. Agora um fato que acontece do outro lado do mundo em poucos minutos é 
REVISTA PAUTA GERAL

ESTUDOS EM JORNALISMO

10.5212/Revista Pauta Gera I.v.4.i2.0001
国

PautaGeral

Estudos em Jornalismo

noticiado aqui no Brasil. Em paralelo ao crescimento desses veículos generalista, houve também o surgimento de jornais locais, voltados para comunidades de uma região, de uma cidade e até de bairros. Esse fenômeno é o chamado hiperlocalismo.

Rocha (2015, p. 56) define hiperlocalismo "como a tendência do jornalismo em explorar temas e discussões de interesse local organizado por regiões, cidades ou bairros". É nesse cenário de mudanças no ecossistema midiático e com a proposta de noticiar fatos e acontecimentos do Bico do Papagaio que surgem os sites Voz do Bico e Folha do Bico.

\section{Voz do Bico}

Com a emancipação do município de Augustinópolis, em 1982, surge um dos primeiros jornais impressos do extremo norte do Tocantins, o Folha do Interior. Criado por Anderson Dias, o jornal permaneceu com esse nome até 1994, quando Paulo Palmares assumiu o comando do periódico, que passou a ser chamado Voz do Bico. Segundo o jornal, a mudança de nome foi para manter uma maior identificação com a região. Com uma visão inovadora, o Voz do Bico foi o primeiro veículo de comunicação do Bico do Papagaio a migrar para as mídias digitais, lançando o site ainda em $1997^{7}$.

No início de setembro de 2017, 20 anos depois de lançar a primeira versão do site, o jornal deu mais um passo de inovação e lançou o aplicativo de notícias para smartphones. Vale destacar que o jornal de referência do estado, o Jornal do Tocantins, ainda não possui aplicativo para celulares. Atualmente, o Voz do Bico (Figura 2) conta com três funcionários fixos, que são os responsáveis pela versão impressa e por alimentarem o site. Há serviços que são terceirizados, como a elaboração de anúncios e a edição de vídeos.

\footnotetext{
7 Informações disponíveis em: ঝttp://www.vozd obico.com.br/bico/voz-do-bico-
} a plica tivo-c elular/ >. Ac essa do em: 09 set 2017. 
REVISTA PAUTA GERAL

ESTUDOS EM JORNALISMO

10.5212/Revista Pauta G era I.v.4.i2.0001

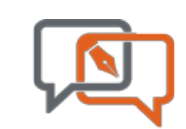

PautaGeral

Estudos em Jornalismo

Figura 02: Capa completa do site Voz do Bico.
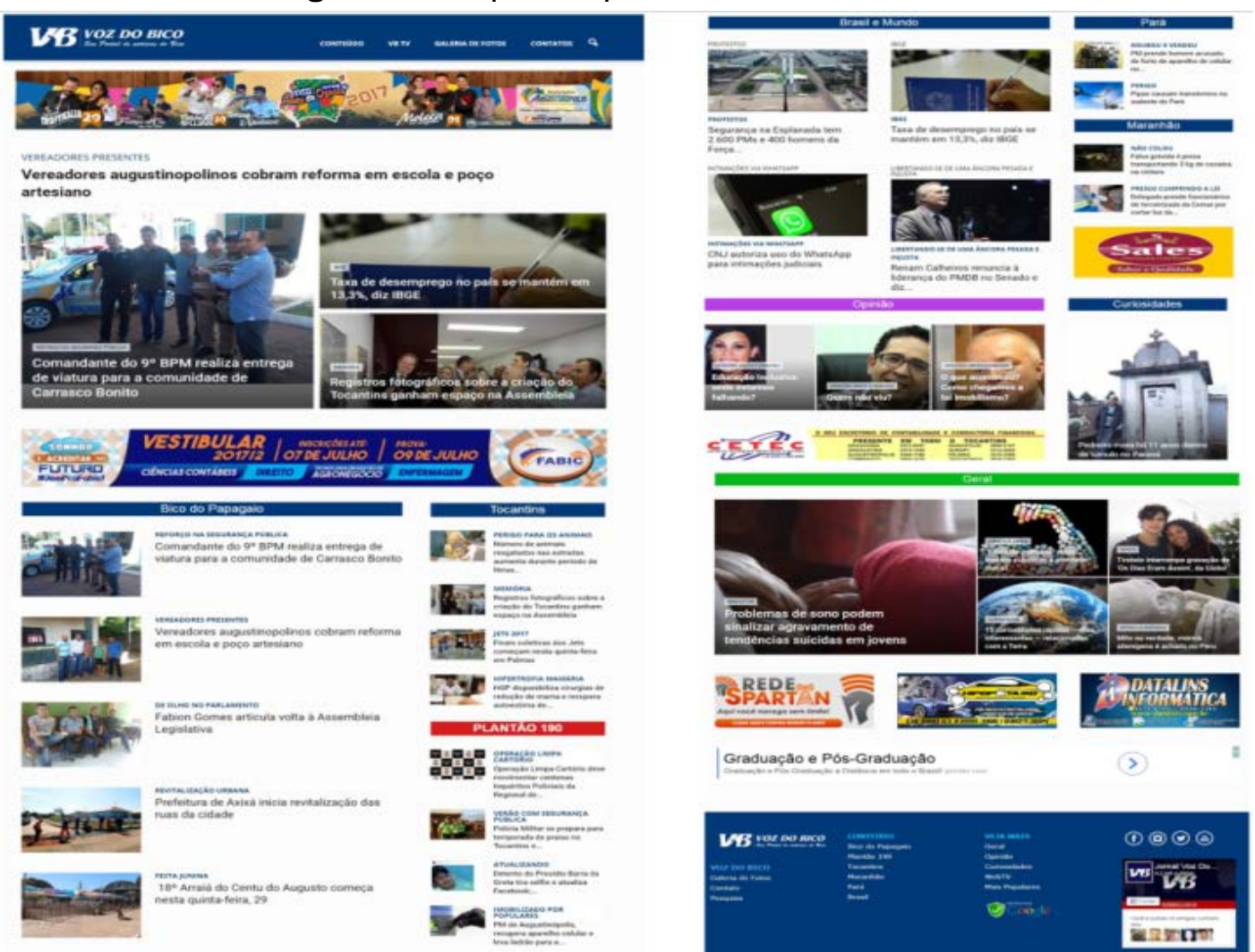

Graduaçăo e Pós-Graduaçá

Fonte: Elaboração dos autores.

O Voz do Bico tem nove editorias, que aparecem na página inicial do site na seguinte ordem: Bico do Papagaio, Tocantins, Ronda 190, Brasil e Mundo, Pará, Maranhão, Opinião, Curiosidades e Geral. Além disso, conta com um espaço dedicado a galerias de fotos e com a VB TV. Na página inicial é apresentada uma manchete no topo da página e logo abaixo três destaques com foto, sendo uma maior e duas menores. No período analisado, de 26 a 30 de junho de 2017, três dos quatro destaques sempre eram de notícias locais, o que demonstra a vocação do site em noticiar a microrregião.

$\mathrm{Na}$ semana de análise foram contabilizadas 82 matérias publicadas no site, somando todas as editorias. Foi possível identificar notícias referentes a nove municípios: Augustinópolis, Araguatins, Praia Norte, Esperantina, Carrasco Bonito, Tocantinópolis, Buriti, Axixá e São Miguel. Todas as notícias foram postadas na editoria Bico do Papagaio. Nesta seção também foram registradas notícias que abordavam a região como um todo, e não apenas fatos isolados de cada município. Foram noticiadas a inclusão de um evento da região no calendário turístico do estado, a articulação de um representante 
REVISTA PAUTA GERAL

ESTUDOS EM JORNALISMO

regional para voltar a assembleia legislativa e o encerramento de uma ação dos deputados estudais que discutiu o desenvolvimento do Bico do Papagaio.

Quadro 1: Notícias e suas receptivas cidade

\begin{tabular}{|c|c|c|c|}
\hline \multicolumn{4}{|c|}{ VOZ DO BICO } \\
\hline & & $\begin{array}{l}\text { Quantidades } \\
\text { de notícias }\end{array}$ & Assuntos \\
\hline \multirow{9}{*}{ Municípios } & Araguatins & 1 & Encontro deputados \\
\hline & Augustinópolis & 5 & $\begin{array}{l}\text { Recupera veículos / prisão / Visita } \\
\text { Sec. Est. De Educação / arraiá municipal / } \\
\text { reforma escola / conselho de saúde }\end{array}$ \\
\hline & Tocantinópolis & 1 & Pagamento $13^{\circ}$ salário / \\
\hline & Praia Norte & 1 & Homicídio \\
\hline & Esperantina & 2 & Inauguração feira / \\
\hline & Buriti & 1 & Dívidas prefeitura \\
\hline & São Miguel & 1 & Recupera veículos / \\
\hline & $\begin{array}{l}\text { Carrasco } \\
\text { Bonito }\end{array}$ & 1 & Entrega carro polícia \\
\hline & Axixá & 2 & Prisão / revitalização ruas / \\
\hline TOTAL & 9 & 15 & \\
\hline
\end{tabular}

Fonte: elaboração dos autores

Em se tratando das notícias locais, foram noticiadas a inauguração da reforma de uma feira em Esperantina, reunião do prefeito de Augustinópolis, reunião com a Polícia Militar para discutir o esquema de segurança nas praias de Praia Norte e Carrasco Bonito, início do arraial em Augustinópolis, pagamento de $13^{\circ}$ salário em Tocantinópolis, cobrança de vereadores de Augustinópolis, homicídio no povoado Jatobal, dívidas da prefeitura de Buriti, dentre outras.

Sobre as demais editorias do Voz do Bico foi possível observar que as seções Pará e Maranhão são atualizadas diariamente com duas notícias por dia. São informações Revista Pauta Geral-Estudos em J omalismo, Ponta Grossa, v. 4, n. 2, p. 3 -20. J ul/Dez 2017. 
REVISTA PAUTA GERAL

ESTUDOS EM JORNALISMO

10.5212/Revista Pauta Gera I.v.4.i2.0001

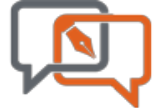

PautaGeral

Estudos em Jornalismo

das cidades próximas do Bico do Papagaio, como Marabá e Parauapebas, no Pará, e Imperatriz e Balsas, no Maranhão. Com relação às editorias Tocantins e Ronda 190, são publicadas mais notícias gerais do estado e notícias policiais, com uma média de publicação de duas a três matérias por dia. Na Ronda 190, nos dias analisados, foram publicadas duas notícias de municípios da região. Uma abordou a apreensão de armas em Axixá e a outra destacou a recuperação de carros roubados em São Miguel e Augustinópolis.

Com relação às editorias Brasil e Mundo e Geral, também foram atualizadas diariamente no período analisado com uma frequência média de três notícias por dia para cada seção. Foram publicadas informações referentes ao Sistema de Seleção Unificada (Sisu), notícias da política nacional e operações da Polícia Federal. Já as editorias Opinião e Curiosidades, além da galeria de fotos e da VB TV, estavam todas desatualizadas. A última galeria de fotos foi publicada no dia 16 de junho. O último vídeo da VB TV foi publicado ainda em abril deste ano. Ou seja, ficou evidente que a preocupação dos funcionários da redação é de atualizar as editorias locais e nacionais, não havendo tanta preocupação com a galeria de fotos e a produção de vídeos.

Diante da descrição apresentada do site, é possível inferir que o site Voz do Bico apresenta características do jornalismo hiperlocal, pois tem uma produção diária de matérias sobre municípios da região, destacando particularidades de cada município e as notícias regionais. Há espaço no site para as notícias gerais sobre o país e o mundo, porém os destaques são dados às matérias que abordam a realidade local. Como exemplo pode-se destacar a notícia sobre as dívidas da prefeitura de Buriti, que ressalta a difícil situação enfrentada pelo município e como a comunidade pode ser afetada.

Como destacam Lemos e Pereira (2011), o jornalismo hiperlocal é caracterizado pela cobertura jornalística com a produção de conteúdos sobre uma comunidade específica, como foi verificado no site Voz do Bico. Bianchi e Moraes Júnior (2016) ressaltam que a imprensa hiperlocal faz um jornalismo mais próximo da comunidade e pautando temas específicos e com foco em uma determinada população, característica nítida nas produções do site analisado, embora as matérias locais são na sua totalidade notícias curtas no formato hard news. No período analisado, não foi registrada nenhuma reportagem mais humanizada sobre as comunidades locais. Porém, os temas abordados são assuntos que afetam diretamente determinado público. 


\section{Folha do Bico}

Há 11 anos no ar, o site Folha do Bico é sediado em Araguatins e tem como diretor responsável Tasso Antônio Cavalcante Passos. Atualmente, conta com três pessoas que alimentam o site, porém só o diretor que escreve, as outras duas pessoas são responsáveis pela apuração. O webjornal conta com seis editorias e uma atualização diária. Com o lema: informação com liberdade de expressão, o site se afirma como plural, independente e o mais dinâmico da região.

Figura 03 - Capa completa do site Folha do Bico
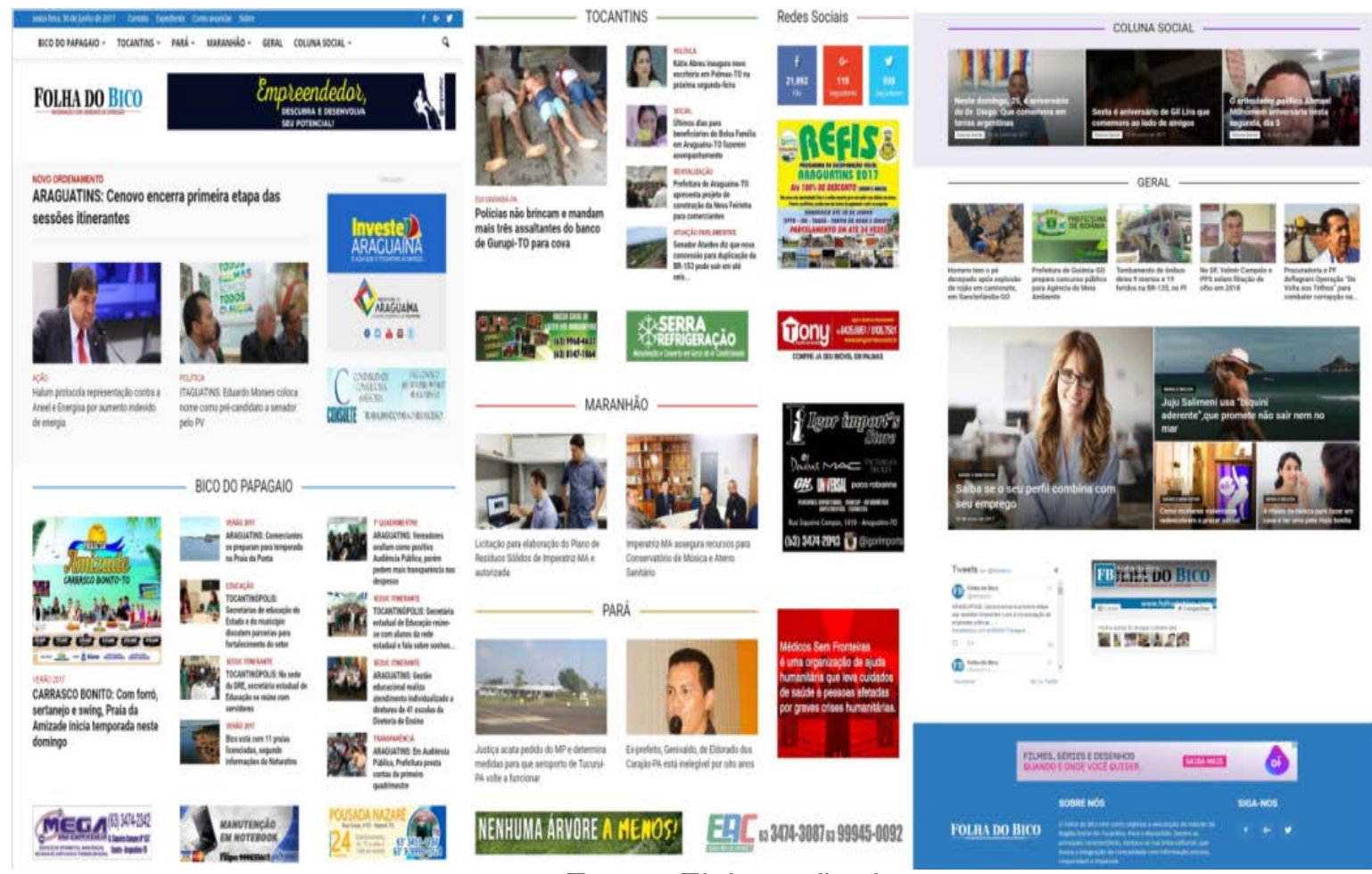

Fonte: Elaboração do autor.

No rodapé da pagina inicial ${ }^{8}$, o site afirma que o objetivo é veicular notícias da região norte do Tocantins, Pará e Maranhão, se destacando por possuir uma linha editorial que busca a integração da comunidade e apresenta informação precisa, responsável e imparcial. Na aba "Sobre", o site não apresenta um histórico do veículo, apenas destaca qualidades da produção desenvolvida e particularidades da cobertura jornalística na região. "Nossa cobertura não tem lados, partidos ou bandeiras, nos

8 Disponível em: বhttp://www.folhadobico.com.br/>. Acesso em: 10 jun. 2017.

Revista Pauta Geral-Estudos em J omalismo, Ponta Grossa, v. 4, n. 2, p. 3 -20. J ul/Dez 2017. 
REVISTA PAUTA GERAL

ESTUDOS EM JORNALISMO

10.5212/Revista Pauta Gera I.v.4.i2.0001

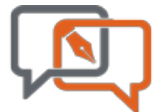

PautaGeral

Estudos em Jornalismo

limitamos apenas a contar o fato, o acontecimento, seja onde tenha ocorrido. Conclusões cabem apenas ao leitor formular, nosso papel é informar" (FOLHA DO BICO, 2017) ${ }^{9}$.

O site é dividido em seis editorias: Bico do Papagaio, Tocantins, Pará, Maranhão, Geral e Coluna Social. No período analisado, as editorias foram atualizadas diariamente, com exceção da Geral e Coluna Social, que estavam desatualizadas, com as últimas postagens feitas no dia 25 de junho. Ao todo, foram contabilizadas 85 notícias durante os cinco dias analisados. Foi verificado que o foco do site são as notícias locais, ou seja, das cidades que compõem o Bico do Papagaio.

Do total de notícias contabilizadas, 48 delas, que representa mais da metade do total, eram de notícias dos municípios da região. Além disso, outras cinco matérias tinham como foco a região como um todo integrado. Das 25 cidades que compõem o Bico, 11 tiveram notícias publicadas nos dias analisados. Os municípios que tiveram mais notícias divulgadas no Folha do Bico foram Araguatins, cidade sede do site, Tocantinópolis e Augustinópolis, como mostra o Quadro 2.

Quadro 2: Notícias e suas receptivas cidade

\begin{tabular}{|c|c|c|}
\hline \multicolumn{3}{|c|}{ FOLHA DO BICO } \\
\hline & $\begin{array}{l}\text { Quantidade } \\
\text { de notícias }\end{array}$ & Assuntos \\
\hline Araguatins & 22 & $\begin{array}{l}\text { Comércio praias / Praias / Polícia / } \\
\text { literatura na praça / Contas Prefeitura / } \\
\text { Parcerias educação / audiência pública / } \\
\text { reabertura banco / Vagas Sine / Política } \\
\text { local / Arraial / reclamação saúde / } \\
\text { encontro professores / festas populares / } \\
\text { assalto banco }\end{array}$ \\
\hline Tocantinópolis & 8 & $\begin{array}{l}\text { Parcerias Educação / } 13^{\circ} \text { servidores / } \\
\text { projeto } 3^{a} \text { idade / ações nas escolas / } \\
\text { Exposição ciências }\end{array}$ \\
\hline $\begin{array}{l}\text { Augustinópoli } \\
\text { S }\end{array}$ & 5 & $\begin{array}{l}\text { Mudanças Arraial / reunião escolas / } \\
\text { Roubos veículos / prisão assaltante / } \\
\text { reunião deputados }\end{array}$ \\
\hline São Bento & 3 & Melhorias saúde / atendimento defensoria \\
\hline
\end{tabular}

9 Disponível em: ঝttp://www.folhadobico.com.br/sobre >. Acesso em: 10 jun. 2017. 


\begin{tabular}{|l|l|c|l|}
\hline \multirow{4}{*}{ Municípios } & & & / Jogos escolares \\
\cline { 2 - 4 } & Axixá & 2 & Apreensão armas / Protesto moradores \\
\cline { 2 - 4 } & Sítio Novo & 2 & Recapeamento ruas / Salário servidores \\
\cline { 2 - 4 } & $\begin{array}{l}\text { Carrasco } \\
\text { Bonito }\end{array}$ & 2 & Melhorias segurança / Abertura praias \\
\cline { 2 - 4 } & Cachoerinha & 1 & Assalto Correios \\
\cline { 2 - 5 } & Sampaio & 1 & Prisão de estuprador \\
\cline { 2 - 5 } & Itaguatins & 1 & Política regional \\
\cline { 2 - 5 } & Praia Norte & 1 & Homicídio \\
\hline \multirow{2}{*}{ TOTAL } & $\mathbf{1 1}$ & $\mathbf{4 8}$ & \\
\hline
\end{tabular}

Fonte: elaboração dos autores

As matérias publicadas abordavam, na maioria das vezes, casos policiais como homicídios, acidentes fatais e prisões. Também foram registradas matérias sobre a situação política dos municípios, educação, recapeamento de ruas, protesto e os preparativos para o período de veraneio. Duas matérias ilustram a característica hiperlocal do site. Uma aborda o trabalho de recapeamento de ruas nos municípios de Sítio Novo, que visa melhorar a vida da população que reclamava das más condições das vias. Já em Axixá, os moradores de um bairro da cidade interditaram uma rua e atearam fogo em pneus e pedaços de madeira como forma de protesto contra as más condições das ruas no bairro.

A partir dos dados coletados e descritos acima, pode-se inferir que o site Folha do Bico, assim como o Voz do Bico, apresenta uma produção hiperlocal voltada para as comunidades do extremo norte do Tocantins. Diferente do Voz do Bico, o site de Araguatins faz questão de destacar já no título das matérias o município do qual tratam as notícias. A semelhança entre os dois sites diz respeito ao formato das produções, são sempre notícias com texto e foto, sem exploração de recursos multimídias, como galerias de fotos, vídeos e áudios. As matérias em destaque no Folha do Bico também foram, no período analisado, as que abordavam os municípios da região. Notícias gerais sobre o Tocantins e os estados vizinhos, Maranhão e Pará, têm espaço no site, porém não ganham muito destaque, assim como as informações sobre o Brasil e o mundo. 


\section{Considerações finais}

O jornalismo hiperlocal é apontado por pesquisadores como uma das possibilidades vantajosas para o cenário atual da comunicação, marcado pela globalização e homogeneização da informação. São muitas as variáveis que podem ser exploradas no webjornalismo hiperlocal, como notícias de bairros, a participação do público, as matérias mais humanizadas e a exploração dos recursos multimídia. Nos dois sites analisados neste trabalho foi possível verificar a exploração de características do jornalismo hiperlocal, com matérias destacando as realidades de cada município e abordando temas de interesse das comunidades locais. Por outro lado, também foi verificado que os dois sites ainda estão presos à linguagem do jornalismo impresso, apenas com publicação de texto e foto.

Foi possível verificar, ainda, que o site Folha do Bico apresenta uma cobertura mais hiperlocal que o webjornal Voz do Bico. Enquanto o primeiro publicou mais de 40 notícias de onze municípios da região, o segundo cobriu oito cidades. Enquanto o Voz do Bico apresenta mais notícias de Augustinópolis e matérias abordando a região como um todo, o Folha do Bico se volta mais para Araguatins, porém apresenta uma cobertura mais equilibradas com várias notícias de Augustinópolis e Tocantinópolis, dois municípios de destaque na região. Outro ponto que vale destacar é o recurso humano na produção desses sites hiperlocais. Os dois contam apenas com três pessoas para alimentar os webjonais, que teoricamente deveriam cobrir os 25 municípios do Bico do Papagaio. Esse número reduzido de pessoas atuando nas redações poder ter influência direta na produção dos veículos, que, na maioria das vezes, não conseguem expandir a cobertura para outros municípios, além de não produzirem novos conteúdos para serem publicados.

Embora os estudiosos da área apontem o jornalismo hiperlocal como uma oportunidade para os profissionais, que podem atuar com a produção de blogs, sites de notícias, redes sociais, percebe-se que há outros fatores que influenciam nesse processo e que podem limitar a produção desenvolvida pelos veículos de comunicação. Os recursos financeiros e humanos são alguns desses fatores que podem interferir diretamente na produção e no resultado final. Os dados apresentados dos sites Folha do Bico e Voz do Bico dão indicativos desse processo. O jornalismo hiperlocal é uma oportunidade no cenário midiático atual, porém requer planejamento e recursos humanos e financeiros para que se possa explorar todas as possibilidades oferecidas pela web. 


\section{Referências}

BIANCHI, M. M. MORAES JÚNIOR. E. Jornalismo hiperlocal na vila mariana: a produção de Pautas a partir da história oral de moradores do bairro. In: SEMINÁRIO DE INICIAÇÃO CIENTÍFICA, 5., 2016, São Paulo. Anais eletrônicos..., São Paulo: Escola Superior de Propaganda e Marketing, São Paulo, 2016. Disponível em: <https://goo.gl/dEFdcB>. Acessado em: 10 jun 2017.

BRONOSKY, M. E.; CARVALHO, J. M. de (Orgs.). Jornalismo e Convergência. $1^{\text {a }}$ ed. São Paulo: Cultura Acadêmica, 2014

CAMPONEZ, C. Jornalismo de proximidade: Rituais de comunicação na imprensa regional. Coimbra: Minerva Coimbra, 2002.

. Jornalismo Regional: proximidade e distanciações. Linhas de reflexão sobre uma ética da proximidade do jornalismo. In: CORREIA, João Carlos (org.). Ágora Jornalismo de proximidade: limites, desafios e oportunidades. Covilhã, UBI: LabCom, 2011.

CASTELLS, M. A. A galáxia da internet: reflexões sobre a internet, os negócios e a sociedade. Rio de Janeiro: Jorge Zahar, 2003.

Para além da caridade: responsabilidade social no interesse da empresa na nova economia. In: CORTINA, A (org.). Construir confiança: ética na empresa na sociedade da informação e das comunicações. São Paulo: Edições Loyola, 2007, p. 55-74.

CLEMENTINO, A. M.; MONTE-MÓR, R. L. M. Grandes Projetos e seus impactos e significados na Região do Bico do Papagaio-TO. In: ENCONTRO NACIONAL DE ESTUDOS POPULACIONAIS, 14, 2004, Caxambu, MG. Anais eletrônicos..., Caxambu, 2004. Disponível em: <https://goo.gl/twnHU2>. Acessado em: 10 jun. 2017.

GARCÍA, X. L. Ciberperiodismo em la proximidade. Sevilla (España): Comunicación Social Ediciones y Publicaciones, 2008.

HALL, S. Identidade cultural na pós-modernidade. 11.ed. Rio de Janeiro: DP\&A, 2006. $102 p$.

JENKINS, H. Cultura da convergência. São Paulo: Aleph, 2009. 
LEMOS, C. E. B.; PEREIRA, R. M. Jornalismo hiperlocal no contexto multimídia: um relato da experiência do jornal-laboratório Contramão Online. In: CONGRESSO BRASILEIRO DE CIÊNCIAS DA COMUNICAÇÃO NA REGIÃO SUDESTE, 16., 2011, São Paulo. Anais eletrônicos..., São Paulo: Fundação Escola de Comércio Álvares Penteado, 2011. Disponível em: <https://goo.gl/EpLE1k>. Acessado em: 10 jun. 2017.

MACEDO, Sandro. Padre Josimo Tavares, mártir na disputa pela posse de terra no país nos anos 80. O Globo, Rio de Janeiro, 09 mai 2016, Acervo O Globo. Disponível em: $<$ http://acervo.oglobo.globo.com/fatos-historicos/padre-josimo-tavares-martir-na-disputapela-posse-de-terra-no-pais-nos-anos-80-19264745>. Acessado em: 06 out. 2017.

MESQUITA, G. B. Intervenho, logo existo: a audiência potente e as novas relações no jornalismo. 2014. 196 f. Tese (Doutorado em Comunicação) - Centro de Artes e Comunicação, Universidade Federal de Pernambuco, Recife, Pernambuco.

MIRANDA, C. M. SANTOS, G. L. R. dos. Mulheres do Bico do Papagaio: questões de gênero e desenvolvimento regional nos municípios de São Miguel e Axixá. RELEM, v. 5, n. 9, p. 74-87, 2014. Disponível em: <https://goo.gl/JXRb1m>. Acessado em: 10 jun. 2017

ROCHA, L. V. Mobilidade, convergência e hiperlocalismo no webjornalismo brasileiro. Revista Interin. Curitiba, v. 20. n.2. p. 43-65, jul./dez. 2015. Disponível em: <http://interin.utp.br/index.php/vol11/article/view/408/pdf>. Acessado em: 10 jun. 2017.

ROCHA, H. C. C. et al. Jornalismo Hiperlocal: inovação e cultura digital. In: $X$ CONFERÊNCIA BRASILEIRA DE MÍDIA CIDADÃ E V CONFERÊNCIA SUL-AMERICANA DE MÍDIA CIDADÃ, 10, 2011, Bauru. Anais eletrônicos..., Bauru: Universidade Estadual Paulista Júlio Mesquita Filho, 2003. Disponível em: <https://goo.gl/3nVgYh>. Acessado em: 10 jun. 2017.

VARELA, J. Jornalismo participativo: O Jornalismo 3.0. Tradução de Vértice Translade. São Paulo: Thomson learning, 2007.

ZAGO, G. S. Informações Hiperlocais no Twitter: Produção Colaborativa e Mobilidade. In: CONGRESSO BRASILEIRO DE CIÊNCIAS DA COMUNICAÇÃO, 32, 2009, Curitiba. Anais eletrônicos... Curitiba: Universidade Positivo, 2009. Disponível em: <https://goo.gl/6nUC4t>. Acesso em 10 jun. 2017.

Recebido em: 10/10/2017

Publicado em: 01/12/2017 